\title{
The current trends of young people choosing a university degree: Interests and expectations
}

\author{
Silvana Bonil ${ }^{\mathrm{a}^{*}}$
}

Maria Susana Icazatti ${ }^{\text {b }}$

Maria Angeles Morell ${ }^{c}$

Sara Romeu ${ }^{\text {d }}$

Suggested Citation:

Abstract 


\section{Introduction}

1.1. Current scenario affecting young people in their transition to the adult world

\subsection{Vocational choice}

2. Method 
Table 1. Interests towards areas of the knowledge of adolescents of the last years of Average level

\section{Results}




\subsection{Analysis of quantitative data}

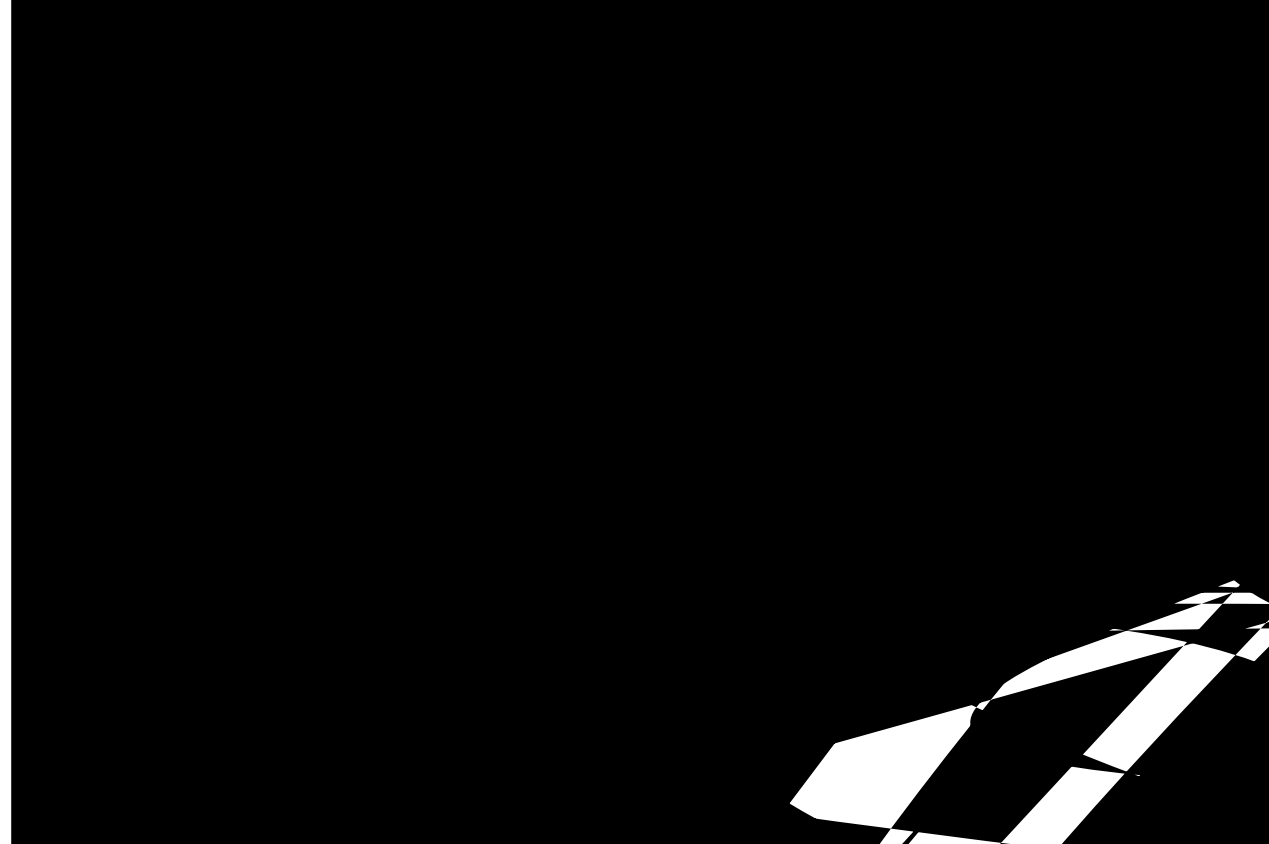

Figure 1. Interest towards areas of knowledge of adolescents in recent years midlevel

Table 2. Motivations towards higher level studies 
New Trends and Issues Proceedings on Humanities and Social Sciences.

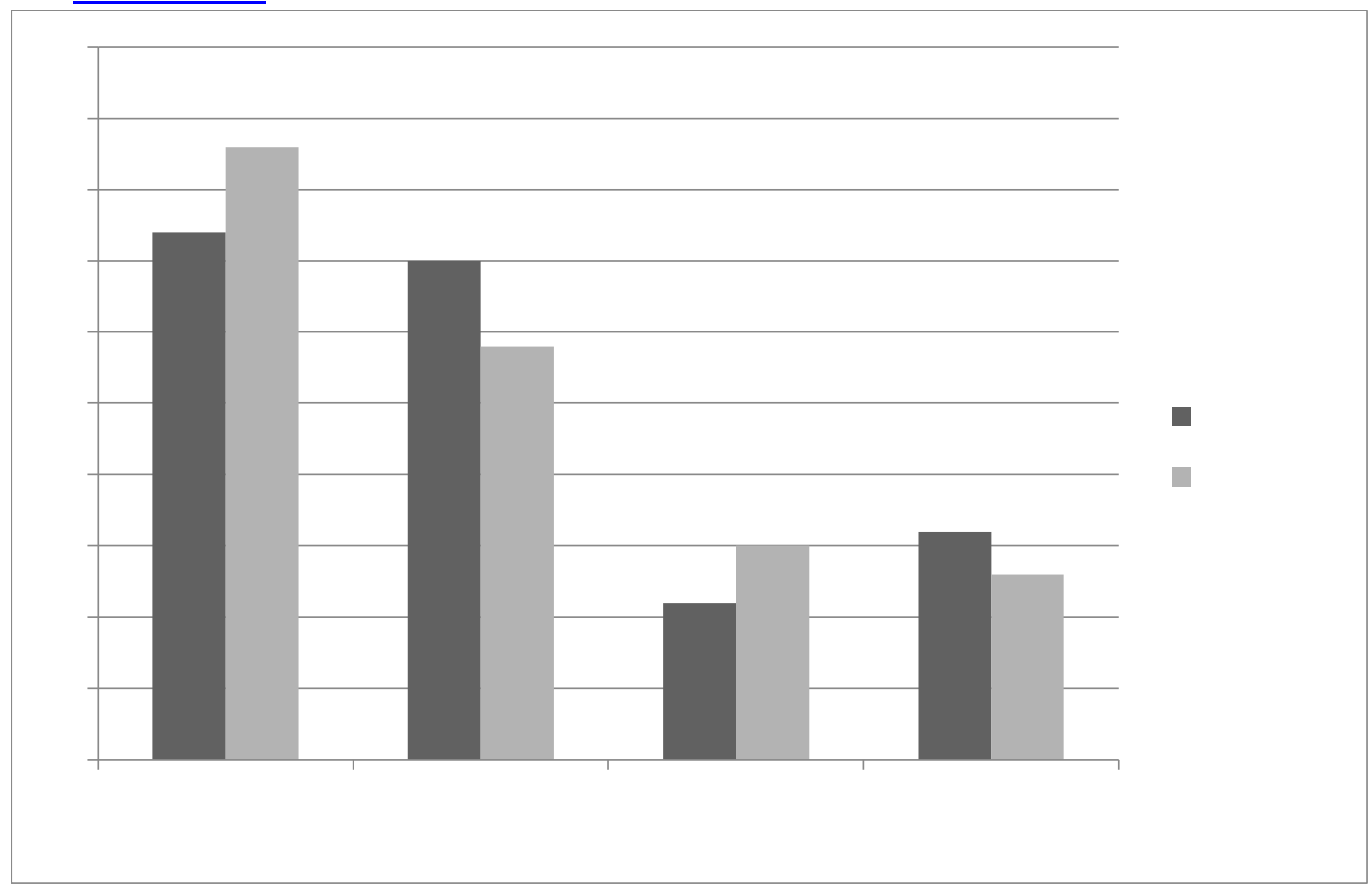

Figure 2. Interest to areas of knowledge of adolescents in recent years midlevel 


\subsection{Analysis of qualitative data}

3.2.1. Interests towards areas of knowledge

3.2.2. Motivations towards higher studies 
3.2.3. Perceptions about the future of the workforce and demand for graduates

3.2.4. Social, family and personal evaluations and considerations of careers and educational institutions

3.2.5. Expectations in the level of difficulty and duration of the races

3.2.6. Assessment of the level of difficulty of the entrance course 
3.2.7. Variable of institutional policies

\subsubsection{Duration of educational programs}

\subsubsection{Schedule of programs}

\subsubsection{Recognition of titles awarded}

\section{Conclusions}


New Trends and Issues Proceedings on Humanities and Social Sciences.

I

\section{References}

Las neuronas de Dios.

Conferencia

internacional, orientación, inclusión social y desarrollo de la carrera.

Orientación vocacional

10

Revista Mexicana de Orientación Educativa, 